\title{
Impact of Different Vegetation Zones on the Velocity and Discharge of Open- Channel Flow
}

\author{
Xiaonan TANG ${ }^{\mathrm{a}, 1}$, Yutong GUAN ${ }^{\mathrm{a}}$ and Yuxiang $\mathrm{HU}^{\mathrm{a}}$ \\ ${ }^{a}$ Department of Civil Engineering, Xi'an Jiaotong-Liverpool University, China
}

\begin{abstract}
Different types of vegetation widely exist in rivers and wetlands. The vegetation will affect the ecological environment and flow process, thus becoming increasingly significant in river engineering and aquatic environmental management. Previous research on vegetated flow is mainly to understand the flow structure of open channels with fully covered one-layer vegetation. However, vegetation often grows along a river bank and co-exists in different heights. The present paper presents experimental results about the flow characteristics of an open-channel with two sides covered by differently layered vegetation, focusing on the effect of vegetation on the velocity distribution and discharge. Two heights of dowels in $10 \mathrm{~cm}$ and $20 \mathrm{~cm}$ were used to simulate rigid vegetation and arranged in a linear form on both sides of a channel bed under emergent and fully submerged flow conditions. The velocity at different positions was obtained using ADV (Acoustic Doppler Velocimetry). Measured results demonstrate that there exists a shear layer between free-flow and vegetated zones, indicating that the flow transition occurs between fast-moving flow in the free zone and slowly obstructed flow in the vegetated zone and induces a high shear layer and transverse coherent vortices near the interface. Furthermore, compared with the emergent condition, the discharge through the free-flow region slightly decreases under full submerged conditions while the discharge in the vegetated region increases, indicating that the vegetation does not significantly change the discharge percentage in the free region. These findings on differently-layered vegetation would help riparian management practices to maintain healthy ecological and habitat zones.
\end{abstract}

Keywords. Vegetated flow, rigid vegetation, velocity distribution, partial vegetation, riparian environment

\section{Introduction}

Vegetation plays an essential role in river ecosystems since the vegetation provides an ecological environment for habitat creation and biodiversity, and it also improves water quality and reduces bank erosion, and so on. In the riparian environment, different types of vegetation grow along natural rivers, and sometimes vegetation is deliberately planted on engineering's purpose or ecological requirement. The riparian vegetation increases the flow resistance because the vegetation induces the additional drag force, thus influencing velocity distribution, Reynolds stress, and turbulence intensity [1-11].

\footnotetext{
${ }^{1}$ Xiaonan Tang, Department of Civil Engineering, Xi'an Jiaotong-Liverpool University, China; E-mail: xiao.tang@xjtlu.edu.cn.
} 
In the past, many researchers have studied the velocity and resistance of flow with single-layered vegetation, where the vegetation was modelled using artificial cylindrical vegetation of rigid or flexible type in laboratory flumes and under either emergent or submerged flow conditions [12-15]. Due to the growing role of vegetation in improving the river ecological environment, recently more researchers have paid attention to understand the physical processes and interactions of flows with vegetation at different scales [16-17].

The complexity of flow through vegetation may be explained by flow mechanisms in the flow depth $[10,18-19]$. The velocity profile can be modelled separately in a layer where each phenomenon can be described [9-11, 15, 19-21]. In recent years, the flow structure of vegetated channels has also been studied through numerical models (e.g., Neary [22]) and numerical simulation using Ansys FLUENT [23-26].

In natural riparian environments, there co-exist various types of vegetation such as grasses, shrubs, trees. Shorter vegetation can be submerged, but the tall vegetation is emergent depending on the flood flow conditions. The flow interacts with differentlayered vegetation, thus leading very complex flow structure. To grasp the role of multiple-layer vegetation to the flow, there is some research on the flow of openchannel with the entire bed covered by an array of tall and short vegetation (e.g., [21, $25,27,28]$ ), whereas numerical modelling was carried out to reveal the flow characteristics of open-channels with patched double-layered vegetation [29]. Most recently, Tang et al. [30-32] undertook an experimental investigation into the openchannel flow where the channel bed was partially covered with double-layer vegetation. However, little research was explored about the impact of non-evenly distributed vegetation along both sides of a channel, which widely exists in rivers.

In the present study, a new formation of vegetation was set up in a tilting rectangular flume, where one side of the bed is covered with single-layer vegetation and the other side with two-layered vegetation in a linear pattern. ADV (Acoustic Doppler Velocimetry) was used to collect the velocity at various locations, aiming at investigating the flow structure in the zones of vegetation and non-vegetation. The present paper mainly studies the lateral variation of velocity and discharge of the vegetated channel in emergent and fully submerged conditions.

\section{Experimental Method}

The experiment was conducted in the $20 \mathrm{~m}$ long water flume at XJTLU (Xián JiaotongLiverpool University). The $20 \mathrm{~m}$ long titling flume of $0.4 \mathrm{~m}$ wide $\times 0.5 \mathrm{~m}$ high rectangular cross-section was set at a bed slope (S) in $0.3 \%$ (figure 1) [33]. The rigid vegetation was simulated by plastic dowels of $6.35 \mathrm{~mm}$ in diameter, whose heights are $0.1 \mathrm{~m}$ (short) and $0.2 \mathrm{~m}$ (tall). Each type of dowel was arranged linearly with $31.75 \mathrm{~mm}$ apart between the centres of dowels. A $10 \mathrm{~mm}$ thick pre-perforated PVC plate is placed on the flume bed and is used to hold the dowels. Figure 1 is the sketch of the flume, where the $4.3 \mathrm{~m}$ long vegetation session starts $8.4 \mathrm{~m}$ from the entrance of the flume and has different arrangements of vegetation on each side of the bed (figure 2). There are only tall dowels in vegetation region 1 (left), and the distance from the centre of the nearest dowel to wall $\mathrm{A}$ is $25.38 \mathrm{~mm}$. In vegetation region 2 (right), there are two rows of short dowels near the free area and two rows of tall dowels near wall $\mathrm{B}$, and the spacing of dowels is the same as that in region 1 . Thus, each vegetation zone has the same width as the free zone, i.e., one-third of the channel width. 
Two types of velocimetry (downward and side-view Nortek micro ADV) were used to measure velocity at various measurement locations in different regions. For most measuring points, the downward ADV was used to obtain $3 \mathrm{D}$ velocities in a vertical except the water surface, where the side-view ADV was used to obtain the data as close to the surface as possible. The sampling time of each measurement was set as 60 seconds. The velocity data of ADV were processed by WinADV software. This experiment includes two flow depths of 9 and $22 \mathrm{~cm}$. The corresponding discharge is 6.1 and $19.49 \mathrm{~L} / \mathrm{s}$, which respectively represent the following two flow conditions: all dowels are emergent, and all dowels are fully submerged.

In the subsequent figures in the Results section, velocities are normalised by shear velocity $\mathrm{u}_{*}$, defined as $\sqrt{g H S}$, where $g, H$ and $S$ are the acceleration of gravity, flow depth and channel bed slope, respectively. The distance $(\mathrm{z})$ above the channel bottom is normalised by the height of short vegetation $(h)$. The measuring locations are coded as follows (see figure 2): BS and BT denote the measuring positions behind the short dowel and the tall dowel respectively, while FR denotes the free zone (i.e., the central zone without vegetation). The other notations are that BSS, BST denote behind and side apart from short and tall dowels, NS is the location next to the short dowel, NT is the location next to tall dowels, and NST is locations next to short and tall dowels.

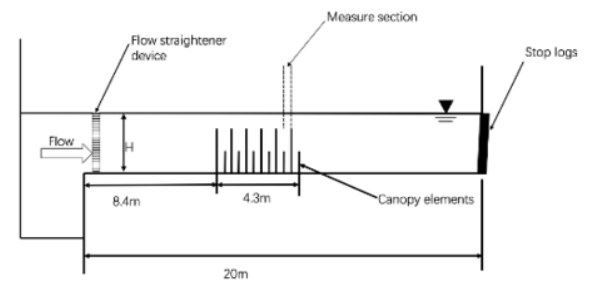

Figure 1. The scheme of the channel.

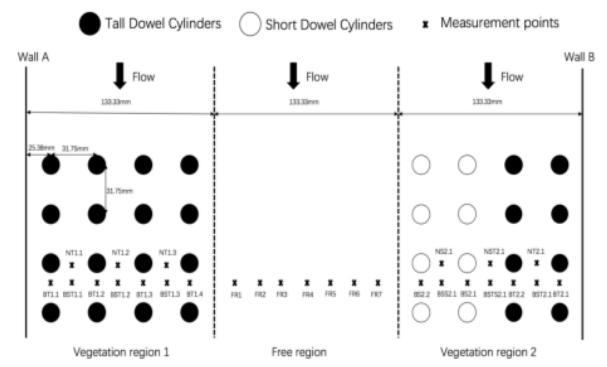

Figure 2. The arrangement of vegetation and measuring positions in the experiment.

\section{Results}

\subsection{Lateral Variation of Velocity}

To understand how boundaries (including the wall and the interface of the vegetation and non-vegetation regions) affect flow velocity, comparisons of velocities at the 
representative locations (i.e., at locations BT, BST, FR, BS and BSS) are shown in figures 3-4 for the cases of flow depths of $9 \mathrm{~cm}$ and $22 \mathrm{~cm}$, respectively.

Figure 3 clearly shows that the velocities in the free region (FR) are much larger than those in the vegetation region. This figure indicates that the vegetation noticeably reduces the velocity. Furthermore, the velocity profile at BT1.4 is larger than the other velocity profiles in the region of vegetation, showing that the flow in the free region has a more significant impact on the vegetation zone closer to the interface. Across the interface, the flow rapidly changes from the free zone to the vegetated zone, inducing strong shear and transverse coherent vortices near the interface [34]. This phenomenon may attribute to an abrupt change of lateral boundary across the interface. Moreover, the intense exchange between the two parts of flow also caused the increased velocity observed in BT1.4 compared with the velocity of different locations in the vegetated region for the case of higher flow (figure 4), where the velocity in the section of short vegetation (BS2.2) is significantly higher compared with that in the section of tall vegetation.

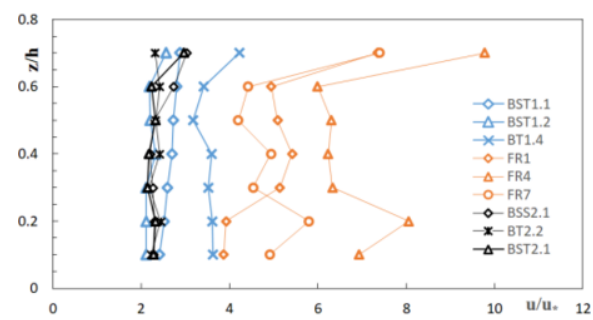

Figure 3. Lateral variation of velocity profile for the flow depth of $9 \mathrm{~cm}$.

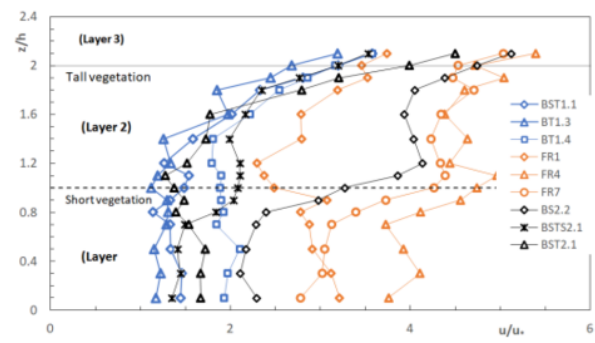

Figure 4. Lateral change of velocity profile for flow depth of $22 \mathrm{~cm}$.

To reveal the lateral variation of velocity, figure 5 presents the lateral change of depth-averaged velocity $\left(\mathrm{U}_{\mathrm{d}}\right)$. Figure 5 demonstrates that the velocity increases fast around the interface from region 1 to the free region and decreases rapidly near the interface from the free region to region 2 for the emergent case $(\mathrm{H}=9 \mathrm{~cm})$. This means that there is an intense momentum exchange near the interface of the two regions. This may be explained by the velocity difference in the two regions, where the flow through the free-flow region is faster than that in the vegetated region. These findings are similar to those observed by Tang et al. $(2018,2019,2021)$. Besides, when the water depth increases to the state of vegetation being full submerged $(\mathrm{H}=22 \mathrm{~cm})$, the lateral change of velocity over the interface becomes relatively small, indicating the relatively weak role of vegetation to the velocity reduction in the vegetated regions, compared with the lower flow case of $\mathrm{H}=9 \mathrm{~cm}$. This result may be attributed to the insignificant influence of vegetation drag on the velocity under full submergence conditions. Also, 
as the water depth increases, the effective flow area in the vegetated regions becomes larger than that in the lower flow depth case, resulting in the relatively small velocity differences between the two regions.

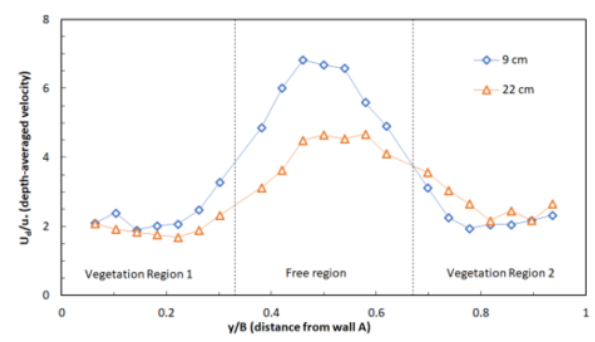

Figure 5. Lateral variation of depth-averaged velocity $(B=40 \mathrm{~cm})$.

\subsection{Discharge Percentage}

The discharge of each zone is computed from figure 5 (the lateral distribution of velocity). Figure 6 illustrates the proportion of discharge at each zone for two flow depths. In figure 6 , it can be seen that in the emergent case, the discharge in the free region is $63.5 \%, 1.8$ times the discharge in the vegetated region, although the total width of the vegetated region is double that of the free region. With the increase of water depth (the fully submerged case), the discharge in the free region decreases, but it increases in each vegetated region, particularly region 2 . This result is due to the change of relative submergence of vegetation. When flow depth changes from $9 \mathrm{~cm}$ to $22 \mathrm{~cm}$, the vegetation in regions 1 and 2 changes from emergent to fully submerged, thus resulting in relatively small resistance due to the vegetation drag. Furthermore, the short vegetation in region 2 has higher submergence, which has less resistance than in fully submerged conditions; consequently, the overall discharge in vegetation region 2 is smaller than that in vegetation region 1.

The observed results reveal that the percentage of discharge through each vegetated zone is much lower (almost 50\% smaller) compared with that in the free zone of the channel (figure 6).

Besides, it appears that as the depth of flow increases from $9 \mathrm{~cm}$ to $22 \mathrm{~cm}$, the percentage of discharge of the free zone slightly decreases from $63.5 \%$ to $55 \%$, whereas the percentage of discharge increases from $18 \%$ to $27 \%$ in region 2 , but the change of discharge is small in region 2. Overall, the discharge percentage through the entire vegetated region increases nearly $10 \%$ from $36.5 \%$ to $45 \%$ as the depth of flow increases from $9 \mathrm{~cm}$ to $22 \mathrm{~cm}$, i.e., from the emergent to fully submerged conditions.

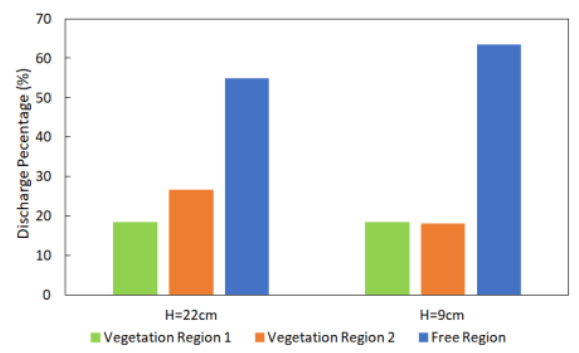

Figure 6. Percentage of discharge in each region for two flow depths: $9 \mathrm{~cm}, 22 \mathrm{~cm}$. 


\section{Conclusions}

Through the novel experimental investigation on the open channel flow covered by different vegetation patterns on each side of the bed under two flow conditions, the results reveal that the velocity decreases in the vegetated region depending on the vegetation pattern. The following points may be drawn:

(1) Across the interface, the flow rapidly changes from the free zone to the vegetated zone, indicating a strong shear layer and transverse coherent vortices around the interface. The velocity profile at BT1.4 near the interface becomes much larger compared with the other velocity profiles in the vegetated zone.

(2) The velocity in the free zone is significantly higher than the velocity in the vegetated zone, indicating that the vegetation has a noticeably retarding role in the flow.

(3) In the free region, the velocity near its centre is larger than that near the vegetation regions.

(4) The discharge in the free region is nearly 1.7 and 1.22 times to the total discharge in the two vegetated regions respectively in emergent and fully-submerged conditions, although the width of the free zone is half the width of the whole vegetated zone, indicating the submergence of vegetation has limited effect on discharge distribution.

\section{Acknowledgements}

The author gratefully acknowledges the financial supports from XJTLU (KSF-E-17, PGRS2012007, RDF-16-02-02, REF-20-02-03) and the National Natural Science Foundation of China (11772270).

\section{References}

[1] Lopez F, Garcia MH. Mean flow and turbulence structure of open-channel flow through nonemergent vegetation. J. of Hydraulic Engineering. 2001 May; 127(5): 392-402.

[2] Ghisalberti M, Nepf $\mathrm{H}$. The structure of the shear layer in flows over rigid and flexible canopies. Environmental Fluid Mechanics. 2006 Jun; 6(3): 277-301.

[3] Nezu I and Sanjou M. Turbulence structure and coherent motion in vegetated canopy open-channel flows. J. of Hydro-Environment Research. 2008 Oct; 2(2): 62-90.

[4] Tang X, Knight DW. Lateral distributions of streamwise velocity in compound channels with partially vegetated floodplains. J. of Science in China Series E: Technological Sciences. 2009 Dec; 52(11): 3357-3362.

[5] Tang X, Sterling M, Knight DW. A general analytical model for lateral velocity distributions in vegetated channels. In River Flow 2010; Dittrich A. Koll K. et al. (Editors) Brundesanstalt fur Wasserbau Germany; 2010; 1: 469-476.

[6] Tang X, Knight DW, Sterling M. Analytical model of streamwise velocity in vegetated channels Proceedings of the Institution of Civil Engineers: Engineering and Computational Mechanics. 2011 Jun; 164(2): 91-102.

[7] Nepf HM. Hydrodynamics of vegetated channels. J. of Hydraulic Research. 2012 May; 50(3): 262-279.

[8] Zhao F, Huai W. Hydrodynamics of discontinuous rigid submerged vegetation patches in open-channel flow. J. of Hydro-environment Research. 2016 Nov; 12:148-60.

[9] Tang X. Methods for predicting vertical velocity distributions in open channel flows with submerged rigid vegetation. In proceedings of the 21st IAHR-APD Congress, 2018 Sept. 2-5; Yogyakarta Indonesia; 1: 567-576.

[10] Tang X. A mixing-length-scale-based analytical model for predicting velocity profiles of open channel flows with submerged rigid vegetation. Water and Environment J. 2019 Nov; 33(4): 610-619. 
[11] Tang X. Evaluating two-layer models for velocity profiles in open-channels with submerged vegetation. J. of Geoscience and Environment Protection. 2019 Jan; 7(1): 68-80.

[12] Nepf HM, Vivoni ER. Flow structure in depth - limited vegetated flow. J. of Geophysical Research. 2000 Dec; 105: 28547-28557.

[13] Carollo FG, Ferro V, Termini D. Flow velocity measurements in vegetated channels. J. of Hydraulic Engineering. 2002 Feb ; 128(7): 664-673.

[14] Stone BM, Shen HT. Hydraulic resistance of flow in channels with cylindrical roughness. J. of Hydraulic Engineering. 2002 Apr; 128(5):500-506.

[15] Tang X, Ali S. Evaluation of methods for predicting velocity profiles in open channel flows with submerged rigid vegetation. In Proceedings of the 35th IAHR World Congress; 2013 Sept. 8-13; Chengdu China; 4: B1, 1-12.

[16] Curran J, Hession W. Vegetative impacts on hydraulics and sediment processes across the fluvial system. J. of Hydrology. 2013 Nov; 505: 364-376.

[17] Chembolu V, Kakati R, Subashisa Dutta S. A laboratory study of flow characteristics in natural heterogeneous vegetation patches under submerged conditions. Advances in Water Resources. 2019 Nov; 133: 103418.

[18] Nikora N. Nikora V, O’Donoghue T. Velocity profiles in vegetated open-channel flows: combined effects of multiple mechanisms. J. of Hydraulic Engineering. 2013 Nov; 139(10):1021-1032.

[19] Huai W, Wang W, Hu Y, Zeng Y, Yang Z. Analytical model of the mean velocity distribution in an open channel with double-layered rigid vegetation. Advances in Water Resources. 2014 Jul; 69:106113.

[20] Singh P, Rahimi H, Tang X. Parameterization of the modeling variables in velocity analytical solutions of open-channel flows with double-layered vegetation. Environmental Fluid Mechanics. 2019 Jan; 19(3): 765-784.

[21] Rahimi H, Tang X, Singh P, Li M, Alaghmand S. Analytical model for the vertical velocity profiles in open channel flows with two layered vegetation. Advances in Water Resources. 2020 Aug; 137(3): 103527.

[22] Neary VS. Numerical solution of fully developed flow with vegetative resistance. J. of Engineering Mechanics. 2003 Apr; 129(5): 558-563.

[23] Souliotis D, Prinos P. Effect of a vegetation patch on turbulent channel flow. J. of Hydraulic Research. 2011 May; 49(2): 157-167.

[24] Anjum N, Ghani U, Pasha GA, Latif A, Sultan T, Ali S. To investigate the flow structure of discontinuous vegetation patches of two vertically different layers in an open channel. Water. 2018 Jan; 10(1):75

[25] Rahimi HR, Tang X, Singh P. Experimental and numerical study on impact of double layer vegetation in open channel flows. J. of Hydrologic Engineering. 2019 Sept; 25(2): 04019064.

[26] Rahimi HR, Tang X, Esmaili Y, Li M, Pourbakhtiar A. Numerical simulation of flow around two sideby-side circular cylinders at high Reynolds number. International J. of Heat and Technology. 2020 Mar; 38(1):77-91.

[27] Liu D, Diplas P, Fairbanks JD, Hodges CC. An experimental study of flow through rigid vegetation. J. of Geophysical Research: Earth Surface. 2008 Mar; 113(F4).

[28] Tang X, Rahimi H, Singh P, Wei Z, Wang Y, Zhao Y, Lu Q. Experimental study of open-channel flow with partial double-layered vegetation. Proceedings of the 1st International Symposium on Water Resource and Environmental Management (WREM 2018); 1-7 ES3-22; 2018 Nov. 28-29; Kunming China. DOI: 10.1051/e3sconf/20198101010.

[29] Anjum N, Tanaka N. Hydrodynamics of longitudinally discontinuous vertically double layered and partially covered rigid vegetation patches in open channel flow. River Research and Application. 2020 Nov; 36(1): 115-127.

[30] Tang X, Rahimi HR, Wang Y, Zhao Y, Lu Q, Wei Z, Singh P. Flow characteristics of open-channel flow with partial two-layered vegetation. Proceedings of the 38th IAHR World Congress; 2019 Sept. 16; Panama City, Panama; DOI: 10.3850/38WC092019-0513.

[31] Tang X, Rahimi HR, Guan Y, Wang Y. Hydraulic characteristics of open-channel flow with partiallyplaced double layer vegetation. Environmental Fluid Mechanics. 2021 Apr; 21(2): 317-342.

[32] Tang $\mathrm{X}, \mathrm{Hu} \mathrm{Y}$. Impact of partially covered vegetation on the lateral velocity distribution of open channel flow. J. of Geoscience and Environment Protection. 2021 Apr; 9(4): 1-10.

[33] Tang X, Guan Y, Zhang Y, Zhang W, Liu T, Yi X. Effect of vegetation on the Flow of a partiallyvegetated channel. IOP Conf. Series: Earth and Environmental Science. 2021 Dec; 668: DOI:10.1088/1755-1315/668/1/012050

[34] Okamoto T, Nezu I. Spatial evolution of coherent motions in finite - length vegetation patch flow. Environmental Fluid Mechanics. 2013 Oct; 13: 417-434. 